\title{
Cocaine Pharmacokinetics in Men and in Women During the Follicular and Luteal Phases of the Menstrual Cycle
}

Jack H. Mendelson, M.D., Nancy K. Mello, Ph.D., Michelle B. Sholar, Arthur J. Siegel, M.D., Marc J. Kaufman, Ph.D., Jonathan M. Levin, M.D., Perry F. Renshaw, M.D., Ph.D., and Bruce M. Cohen, M.D., Ph.D.

Preclinical and clinical studies suggest that females may be less vulnerable to cocaine's toxic effects than males. The pharmacokinetics of intravenous cocaine $(0.2$ and $0.4 \mathrm{mg} /$ $\mathrm{kg}$ ) were measured in 12 men and 22 women with a history of cocaine abuse, matched with respect to age and body mass index (BMI). Women were studied during the follicular and the luteal phases of the menstrual cycle. There were no differences between men and women in pharmacokinetic measures [peak plasma cocaine levels (Cmax), elimination half-life (T 1/2 min), area under the curve (AUC)] or cardiovascular or subjective effects "high" measures. Heart rate increases were cocaine dose-related $(\mathrm{p}<.01-.02)$ and also did not differ between men and women. Cocaine's pharmacokinetic and pharmacodynamic effects were similar in men and women, and in women during the follicular and mid-luteal phases of the menstrual cycle.

[Neuropsychopharmacology 21:294-303, 1999] (C) 1999 American College of Neuropsychopharmacology. Published by Elsevier Science Inc.
KEY WORDS: Cocaine; Pharmacokinetics; Men; Women; Luteal; Follicular

The possibility that gender-related factors may influence the biological consequences of cocaine exposure was first suggested in 1932 by the observation that female rats were more resistant to cocaine toxicity than males (Downs and Eddy 1932). These observations were reconfirmed in 1965 (Guerrero et al. 1965). Subsequently, it was found that estradiol administration to female rats reduced the toxic effects of cocaine and resulted in significantly lower levels of cocaine in plasma in comparison to females who did not receive estradiol

From the Alcohol and Drug Abuse Research Center, Harvard Medical School/McLean Hospital, Belmont, MA.

Address correspondence to: Jack H. Mendelson, M.D., Alcohol and Drug Abuse Research Center, McLean Hospital, 115 Mill Street, Belmont, MA 02478.

Received October 7, 1998; revised December 30, 1998; accepted February 11, 1999.
(Rapp et al. 1979; Selye 1971). These data suggested that estradiol levels might be an important determinant of differences in susceptibility to cocaine-induced lethality in rodents (Dickerson et al. 1991; Morishima et al. 1993). Cardiovascular toxicity was significantly greater in male and ovariectomized rats than in gonadally intact female rodents at lower doses of cocaine (Morishima et al. 1993). However, behavioral studies of the effects of cocaine in rodents have not reported consistent gender differences. Enhanced behavioral effects of cocaine in males (Morse et al. 1993) or females (Glick et al. 1983; Haney et al. 1994; van Haaren and Meyer 1991) and no differences in cocaine's behavioral effects in male and female rodents (Craft and Stratmann 1996; Haney et al. 1995; van Haaren and Hughes 1990) have been reported.

Gender differences in neuroendocrine responses to cocaine have also been reported. Cocaine stimulated a greater increase in adrenocorticotropic hormone (ACTH) in female rats than in male rats and ovariectomy de- 
creased the ACTH response to cocaine (Kuhn and Francis 1997). In rhesus monkeys, the effects of cocaine on anterior pituitary hormones also appears to be modulated by ovarian steroid hormone levels. Cocaine did not stimulate $\mathrm{LH}, \mathrm{FSH}$, or ACTH in ovariectomized rhesus females (Mello et al. 1995; Sarnyai et al. 1995) as it did in gonadally intact rhesus males and females (Mello et al. 1990, 1993; Sarnyai et al. 1996) and human males (Heesch et al. 1996; Mendelson et al. 1992). Since synthetic luteinizing-hormone-releasing-hormone (LHRH) and corticotropin releasing factor (CRF) each stimulated release of its anterior pituitary target hormone in the same ovariectomized rhesus females, we concluded that an absence of gonadal steroid hormones, rather than impaired pituitary responsivity, may have contributed to this effect (Mello et al. 1995; Sarnyai et al. 1995).

Despite the interesting questions posed by these preclinical studies, the issue of possible gender differences in cocaine's pharmacokinetics has received surprisingly little attention in clinical investigations. Since 1977, 11 studies have been conducted with a total of 76 subjects (Barnett et al. 1981; Chow et al. 1985; Cone 1995; Cone et al. 1988; Cook et al. 1985; Evans et al. 1996; Isenschmid et al. 1992; Javaid et al. 1978, 1983; Jeffcoat et al. 1989; Kogan et al. 1977). The most recent studies were conducted with six males (Cone 1995) and nine males (Evans et al. 1996). It is not clear if earlier reports in Science (Javaid et al. 1978) and Biopharmacology Drug Disposition (Javaid et al. 1983) included both men and women. Subjects were described as "adult volunteers," but their gender was not described (Javaid et al. 1978, 1983). Only one study specifically identified participation by a female subject (Chow et al. 1985). In that study, the plasma cocaine half-life was lower in the woman T 1/2 (31 minutes) than in the four men (42-63 minutes).

If there were significant gender differences in the rate of clearance of cocaine in plasma, this could have implications for our understanding of differences in vulnerability to cocaine's toxic effects observed in males and females in preclinical studies. Gender differences in cocaine's pharmacokinetics could also influence the effectiveness of pharmacologically-based treatment. The influence of the hormonal milieu on the pharmacokinetics and the pharmacodynamics of drugs has become an issue of increasing concern since 1993 when the FDA revised its policy and required the inclusion of women in clinical trials (FDA 1993a, b; Merkatz et al. 1993). Specifically, it has been postulated that variations in gonadotropin and ovarian steroid hormone levels across the menstrual cycle may change the pharmacokinetics and pharmacodynamics of various treatment medications (FDA 1993a, b; Merkatz et al. 1993). In the present study, we examined the pharmacokinetics of cocaine in men and women at two phases of the menstrual cycle, the follicular phase and the mid-luteal phase. These menstrual cycle phases were selected for study in part, because preclinical studies (Dickerson et al. 1991; Guerrero et al. 1965; Mello et al. 1995; Morishima et al. 1993; Rapp et al. 1979; Sarnyai et al. 1995) suggest that ovarian steroid hormones may modulate the biological and behavioral effects of cocaine. However, the contribution of menstrual cycle phase was not evaluated in these women. During the follicular phase of the menstrual cycle, levels of estrogen and progesterone are relatively low whereas during the mid-luteal phase, ovarian steroid hormone levels are high (Yen 1991).

Levin and his associates (1994) have reported gender differences in cerebral perfusion associated with cocaine abuse. Cocaine-dependent women were found to have fewer abnormalities than cocaine-dependent men in cerebral perfusion studies determined with (HMPAO) SPECT procedures. We compared cocaine's pharmacokinetics in the present study for follicular and luteal menstrual cycle phases to evaluate the possible contribution of ovarian steroid hormones to cocaine's effects in women.

\section{METHODS}

\section{Subjects}

Twenty-two adult females and 12 males provided informed consent for participation in this study. The study was approved by the Institutional Review Board of the McLean Hospital. Only healthy men and women who fulfilled DSM-IV diagnostic criteria for cocaine abuse (305.6) were selected. Volunteers with any lifetime DSM-IV Axis 1 disorder other than cocaine abuse and nicotine dependence were excluded. Women who were using oral contraceptive medication were also excluded. Pregnancy tests (hCG C6 subunit blood tests) were completed on the morning before cocaine administration to ensure that no women had become pregnant since pre-study screening. A number of diagnostic instruments including the Health Status and Drug and Alcohol Use History Questionnaires, and a Gynecological History Assessment Form were completed prior to subject selection. All men and women selected for study were in good physical health and had normal medical and laboratory screening examinations. All subjects were drug-free at the time of the study as assessed by urine drug screens (Triage ${ }^{\circledR}$ Biosite Diagnostics, San Diego, CA).

One goal of this study was to assess the influence of changes in the hormonal milieu across the menstrual cycle on cocaine's pharmacokinetics and associated cardiovascular and subjective effects in women. Women were studied in the follicular (5-9 days following the onset of menses) and the luteal phases of the menstrual cycle (18-22 days after the onset of menses). Progester- 
one and estradiol levels were obtained on the day of the study to verify menstrual cycle phase.

\section{Cocaine Dose Selection}

Two doses of intravenous cocaine $(0.2$ and $0.4 \mathrm{mg} / \mathrm{kg})$ were studied in 12 men and in 22 women during the follicular and mid-luteal phases of the menstrual cycle. The low dose of cocaine $(0.2 \mathrm{mg} / \mathrm{kg}$, i.v. $)$ usually produces peak plasma cocaine levels of approximately 100 $\mathrm{ng} / \mathrm{ml}$. The higher dose $(0.4 \mathrm{mg} / \mathrm{kg}$, i.v. $)$ usually produces peak plasma cocaine levels over $200 \mathrm{ng} / \mathrm{ml}$. These doses of cocaine have proved to be safe and induce significant changes in mood states and physiological responses in previous clinical studies with men (Evans et al. 1996; Foltin and Fischman 1991; Kaufman et al. 1998; Teoh et al. 1993). Six men received an i.v. dose of cocaine of $0.2 \mathrm{mg} / \mathrm{kg}$, and six men received an i.v. dose of cocaine of $0.4 \mathrm{mg} / \mathrm{kg}$. Five women received an i.v. dose of cocaine of $0.2 \mathrm{mg} / \mathrm{kg}$ during the follicular phase of the menstrual cycle, and five women received an i.v. dose of cocaine of $0.2 \mathrm{mg} / \mathrm{kg}$ during the luteal phase of the menstrual cycle. Six women received an i.v. dose of cocaine of $0.4 \mathrm{mg} / \mathrm{kg}$ during the follicular phase of the menstrual cycle, and six women received an i.v. dose of cocaine of $0.4 \mathrm{mg} / \mathrm{kg}$ during the luteal phase of the menstrual cycle.

\section{Cocaine Administration Procedures}

These studies were carried out on a clinical research ward. Cocaine $(0.2$ or $0.4 \mathrm{mg} / \mathrm{kg})$ was administered intravenously over an interval of one minute. Subjects were studied in a semi-supine position, and heart rate, blood pressure and electrocardiograms (EKG) were continuously monitored for ten min prior to intravenous cocaine administration and for two hours following intravenous injection with a Hewlett-Packard EKG monitor (Model 78 352A). A physician certified in cardiopulmonary resuscitation was present during each study, and a cardiac defibrillator and appropriate emergency treatment medications were located on the clinical research ward.

Samples for analysis of plasma cocaine were collected at baseline prior to i.v. cocaine injection and at 2 , $4,8,12,16,20,30,40,60,80,120,180$, and 240 minutes following completion of cocaine injection. This sampling frequency was based on our previous observations that cocaine levels in plasma increase rapidly within two minutes after intravenous administration (Sarnyai et al. 1995; Sholar et al. 1998; Teoh et al. 1994). All plasma samples for cocaine analysis were collected from an intravenous catheter in the arm opposite the arm in which cocaine was injected intravenously. Blood samples were collected and transferred to heparinized Vacutainer tubes containing sodium fluoride and acetic acid (to prevent the hydrolysis of cocaine) then iced immediately, centrifuged and plasma was removed and frozen at $-70^{\circ} \mathrm{C}$ for cocaine analysis.

\section{Cocaine Hydrochloride Preparation}

Cocaine hydrochloride was acquired from the National Institute of Drug Abuse in powder form and was dissolved in sterile water for intravenous injection by the McLean Hospital pharmacy. Sterility was ensured by passing the solution through a 0.22 micron millipore filter and subjecting it to a Limulus Amebocyte Lysate (LAL) test for detection of gram negative bacterial endotoxins. The test kit is manufactured by Whittaker Bioproducts, Walkersville, MD.

\section{Estradiol Assay}

Serum estradiol was determined in duplicate by a direct, double antibody RIA method, using kits purchased from Diagnostic Product Corporation (Los Angeles, CA). The assay sensitivity was $1.1 \mathrm{pg} / \mathrm{ml}$ and the intra- and interassay coefficients of variation were $2.0 \%$ and $7.8 \%$, respectively.

\section{Progesterone Assay}

Serum progesterone was determined in duplicate by Coat-A-Count RIA method, using kits purchased from Diagnostic Products Corporation (Los Angeles, CA). The assay sensitivity was $0.06 \mathrm{ng} / \mathrm{ml}$ and the intra- and interassay coefficients of variation were $4.0 \%$ and $5.1 \%$, respectively.

\section{Plasma Cocaine Analysis}

Plasma cocaine levels were measured in duplicate using a solid phase extraction method described by SPEC Instruction Manual by Ansys with a Hewlett-Packard 5890 Series II gas chromatograph, equipped with a capillary column and a Hewlett-Packard 5971 Series Mass Selective detector (Abusada et al. 1993). The assay sensitivity was $10 \mathrm{ng} / \mathrm{ml}$ and the intra- and interassay coefficients of variation were $2.0 \%$ and $2.9 \%$, respectively.

\section{Pharmacokinetic Analysis}

Estimates of cocaine's primary kinetic parameters (i.e., rate constants, apparent volume of distribution, and time to peak plasma concentration) and secondary parameters (i.e., area under the curve, initial and terminal phase half-lives) were obtained directly from a non linear regression estimation software program (WinNon$\operatorname{lin}^{\mathrm{TM}}$ Version 1.5, Scientific Consulting, Inc. Apec, NC). Plasma drug concentrations were fitted to a single dose, 
one compartment model with bolus input, first order output and elimination. Plasma concentrations were weighted by the reciprocal of the predicted concentrations. Area under the curves $\left(\mathrm{AUC}_{0-240 \mathrm{~min}}\right)$ were estimated by the linear trapezoidal rule. Estimates of T1/2 (half-life) were obtained from the computer fitted model. Pharmacokinetic parameters were analyzed with a one-way analysis of variance (ANOVA) to determine if there were differences between genders and/or between menstrual cycle phases.

A two-compartment model for cocaine pharmacokinetic analysis was not used in this study, because blood sample collections were carried out for only $260 \mathrm{~min}-$ utes (20 min prior to and $240 \mathrm{~min}$ following i.v. cocaine administration). The blood sampling procedures in this study permitted cocaine pharmacokinetic analysis by a one-compartment model and also provided a sufficient number of blood samples for analysis of neuroendocrine hormones (Mendelson et al. 1998). Institutional Review Board approval permitted collection of a total of approximately $200 \mathrm{ml}$ of blood from each subject.

\section{Subjective Effects Measures}

Subjective reactions to cocaine were assessed with a simple visual analogue scale. This self-report rating scale was selected because it has been sensitive to cocaine dose effects in our previous studies (Kaufman et al. 1998; Mendelson et al. 1998). Subjects were asked to rate drug intensity or "high."

\section{Data Analysis}

Progesterone and estradiol levels during the follicular and luteal phases of the menstrual cycle were analyzed with a two-way ANOVA for menstrual cycle phase and cocaine dose. Plasma cocaine values for subjects were analyzed using a 3 (group) $\times 14$ (time) repeated measures ANOVA. Heart rate as well as systolic and diastolic pressure were analyzed using a 3 (group) $\times 9$ (time) repeated measures ANOVA. If significant main effects were detected, one-way ANOVA's were performed to identify the times at which groups differed significantly. Subjective behavioral responses were analyzed with a one-way ANOVA. Dunnett's (two-tailed) tests were performed to examine group differences. The statistical significance of temporal covariance between plasma cocaine levels and heart rate and subjective effects was evaluated with correlational analyses. Graphic displays of cardiovascular measures (Figure 1) are presented as the change from pre-cocaine baseline levels to facilitate comparisons between men and women. Men had significantly higher baseline systolic blood pressure than women $(p<.05)$.

\section{RESULTS}

\section{Subjects}

Radioimmunoassay of ovarian steroid hormone levels confirmed that women were in the mid-follicular phase or the mid-luteal phase of the menstrual cycle on the day of the study. Average estradiol and progesterone levels during each phase of the menstrual cycle for each cocaine dose group are summarized in Table 1. Average estradiol and progesterone levels during the luteal phase were significantly higher than during the follicular phase $(p<.0001)$ in both the 0.2 and the $0.4 \mathrm{mg} / \mathrm{kg}$ cocaine dose groups. Steroid hormone levels at each phase of the menstrual cycle were also closely matched in women given 0.2 and $0.4 \mathrm{mg} / \mathrm{kg}$, i.v. of cocaine. Estradiol levels in the two cocaine dose groups were equivalent during the follicular phase and during the luteal phase. Similarly, progesterone levels during the follicular phase and during the luteal phase did not differ significantly in the two cocaine dose groups.

The age, weight, height and body mass index (BMI) of the men and the follicular and luteal phase women are shown in Table 2 and Table 3. There were no statistically significant differences between men and women with respect to age and BMI, but men were significantly taller than women $(p<.001)$.

\section{Cocaine Plasma Levels and Pharmacokinetic Profiles}

All baseline plasma samples prior to intravenous cocaine injection were negative for plasma cocaine. Peak plasma cocaine levels were cocaine-dose dependent in all groups. In men, the average peak cocaine levels reached after administration of $0.4 \mathrm{mg} / \mathrm{kg}$ cocaine $(231.3 \pm 22.7 \mathrm{ng} / \mathrm{ml})$ were significantly higher than after administration of $0.2 \mathrm{mg} / \mathrm{kg}$ cocaine $(110.8 \pm 17.5)$ $(p<.002)$. Cocaine plasma levels were maximal within 6-8 minutes after cocaine administration and remained elevated for 60-80 minutes. A similar profile of plasma cocaine levels was observed in women during the follicular and luteal phases of the menstrual cycle. Peak plasma cocaine levels after $0.4 \mathrm{mg} / \mathrm{kg}$, i.v. cocaine were significantly higher than after $0.2 \mathrm{mg} / \mathrm{kg}$, i.v. in women at both phases of the menstrual cycle $(p<.003)$. Peak plasma cocaine levels after $0.2 \mathrm{mg} / \mathrm{kg}$ cocaine averaged $125.9 \pm 16.3 \mathrm{ng} / \mathrm{ml}$ in follicular phase women and 88.1 $\pm 20.1 \mathrm{ng} / \mathrm{ml}$ in luteal phase women. Although plasma cocaine levels were lower during the luteal phase, these values did not achieve statistical significance $(p=.18)$. Peak plasma cocaine levels after $0.4 \mathrm{mg} / \mathrm{kg}$ cocaine averaged $285.3 \pm 24.8 \mathrm{ng} / \mathrm{ml}$ and $271.8 \pm 36.3 \mathrm{ng} / \mathrm{ml}$ during the follicular and the luteal phases of the menstrual cycle respectively, and these levels were not statistically different.

Pharmacokinetic analyses of plasma cocaine levels were performed on data from each cocaine dose group 
Table 1. Ovarian Steroid Hormone Levels in Women

\begin{tabular}{|c|c|c|c|c|}
\hline \multirow[b]{2}{*}{ Cocaine Dose } & \multicolumn{2}{|c|}{ Follicular Phase } & \multicolumn{2}{|c|}{ Luteal Phase } \\
\hline & Estradiol (pg/ml) & Progesterone (ng/ml) & Estradiol (pg/ml) & Progesterone (ng/ml) \\
\hline $0.2 \mathrm{mg} / \mathrm{kg}$, i.v. & $29.6 \pm 8.5$ & $0.51 \pm 0.08$ & $118.6 \pm 21.9$ & $6.41 \pm 1.30$ \\
\hline $0.4 \mathrm{mg} / \mathrm{kg}$, i.v. & $39.4 \pm 9.4$ & $0.62 \pm 0.12$ & $106.2 \pm 16.2$ & $6.42 \pm 1.15$ \\
\hline $\bar{x}$ & $35.0 \pm 6.3$ & $0.57 \pm 0.07$ & $111.9 \pm 12.8$ & $6.41 \pm 0.82$ \\
\hline
\end{tabular}

for men and women to permit quantitative comparisons. Table 4 summarizes the pharmacokinetic analyses for plasma cocaine levels after administration of 0.2 $\mathrm{mg} / \mathrm{kg} /$ i.v. and Table 5 summarizes pharmacokinetic analyses for plasma cocaine levels after administration $0.4 \mathrm{mg} / \mathrm{kg}$, i.v. Each table compares the time to reach peak levels of cocaine in plasma [Tmax (min)]; the peak levels of cocaine in plasma [Cmax $(\mathrm{ng} / \mathrm{ml})]$, the elimination half-life of cocaine in plasma [T1/2 ( $\mathrm{min})]$ and the area under the plasma cocaine curves [AUC (ng. $\mathrm{min} / \mathrm{ml})]$ for men and for women during the follicular phase and the luteal phase of the menstrual cycle. There were no statistically significant differences between any of these pharmacokinetic measures after administration of $0.2 \mathrm{mg} / \mathrm{kg}$ cocaine. The only significant difference in any parameter was measured after administration of $0.4 \mathrm{mg} / \mathrm{kg}$, i.v. cocaine where follicular phase women reached peak cocaine levels more rapidly (Tmax) than men or luteal phase women $(p<.05)$. Although the Tmax for women who received $0.4 \mathrm{mg} / \mathrm{kg}$ cocaine during the follicular phase of the menstrual cycle was statistically significantly different from the Tmax in males, it was only 2.7 min different from females who received $0.4 \mathrm{mg} / \mathrm{kg}$ of cocaine during the luteal phase of the menstrual cycle.

Dose-related statistical analysis for men and women who received 0.2 or $0.4 \mathrm{mg} / \mathrm{kg}$ of cocaine revealed no statistically significant differences for Tmax. No doserelated statistically significant differences were found for $\mathrm{T} 1 / 2$. However, as anticipated, the Cmax was significantly different as a function of dose for all men and women $(p<.0002, .0006$, and .0024). There were also statistically significant dose-related AUC values for all men and women $(p<.0002, .0005$, and .004).

\section{Cardiovascular Effects of Cocaine}

Increases in heart rate after $0.4 \mathrm{mg} / \mathrm{kg}$ cocaine were significantly greater than after $0.2 \mathrm{mg} / \mathrm{kg}$ cocaine in all groups $(p<.01-.02)$, but changes in blood pressure did not differ as a function of cocaine dose. Heart rate as well as systolic and diastolic blood pressure increased significantly above baseline within 1 to 3 minutes after administration of 0.2 and $0.4 \mathrm{mg} / \mathrm{kg}$ cocaine in all groups $(p<.05)$ (Figure 1). Peak increases in heart rate occurred at 9 minutes after cocaine injection in both men and women, but this increase was not sustained. There were no significant differences in heart rate between men and women at either dose of cocaine. Also, there were no significant differences in heart rate between follicular and luteal phase women at either dose of cocaine (Figure 1).

Increases in heart rate (bpm) in men and women after each dose of cocaine are summarized as follows: in men, after $0.2 \mathrm{mg} / \mathrm{kg}$ cocaine, heart rate increased by $27.2 \pm 5.9 \mathrm{bpm}$ to average peak levels of $88.1 \pm 4.8 \mathrm{bpm}$. After $0.4 \mathrm{mg} / \mathrm{kg}$ cocaine, heart rate increased by $48.3 \pm$ $7.2 \mathrm{bpm}$ to average peak levels of $108.8 \pm 8.96 \mathrm{bpm}$. In follicular phase women, heart rate increased by $20.8 \pm$ $3.2 \mathrm{bpm}$ after $0.2 \mathrm{mg} / \mathrm{kg}$ cocaine to average peak levels of $81.3 \pm 2.7 \mathrm{bpm}$. After $0.4 \mathrm{mg} / \mathrm{kg}$ cocaine, heart rate increased by $46.2 \pm 10.3 \mathrm{bpm}$ to average peak levels of $108.0 \pm 10.82 \mathrm{bpm}$. In luteal phase women, heart rate increased by $26.0 \pm 2.8 \mathrm{bpm}$ after $0.2 \mathrm{mg} / \mathrm{kg}$ cocaine to

Table 2. Subject Characteristics $-0.2 \mathrm{mg} / \mathrm{kg}$ Cocaine Dose Group

\begin{tabular}{|c|c|c|c|}
\hline Age (years) & Weight (kgs) & Height (cms) & BMI $\left(\mathrm{kg} / \mathrm{m}^{2}\right)$ \\
\hline \multicolumn{4}{|c|}{ Males $(n=6)$} \\
\hline $\bar{x} 27.00$ & $72.58^{a}$ & 169.58 & 23.75 \\
\hline SE 2.21 & 3.76 & 2.53 & 0.71 \\
\hline \multicolumn{4}{|c|}{ Female Follicular Phase Group $(n=5)$} \\
\hline$\overline{\mathrm{x}} 23.80$ & 56.49 & 162.04 & 22.00 \\
\hline SE 0.86 & 2.77 & 1.47 & 1.48 \\
\hline \multicolumn{4}{|c|}{ Female Luteal Phase Group $(n=5)$} \\
\hline $\bar{x} 26.60$ & 63.57 & 168.15 & 23.40 \\
\hline SE 2.73 & 5.04 & 3.15 & 1.83 \\
\hline
\end{tabular}

${ }^{a}$ Males weighed significantly more $(p=.03)$ than follicular phase women. 


\section{Cardiovascular Effects of Cocaine in Men and Women}
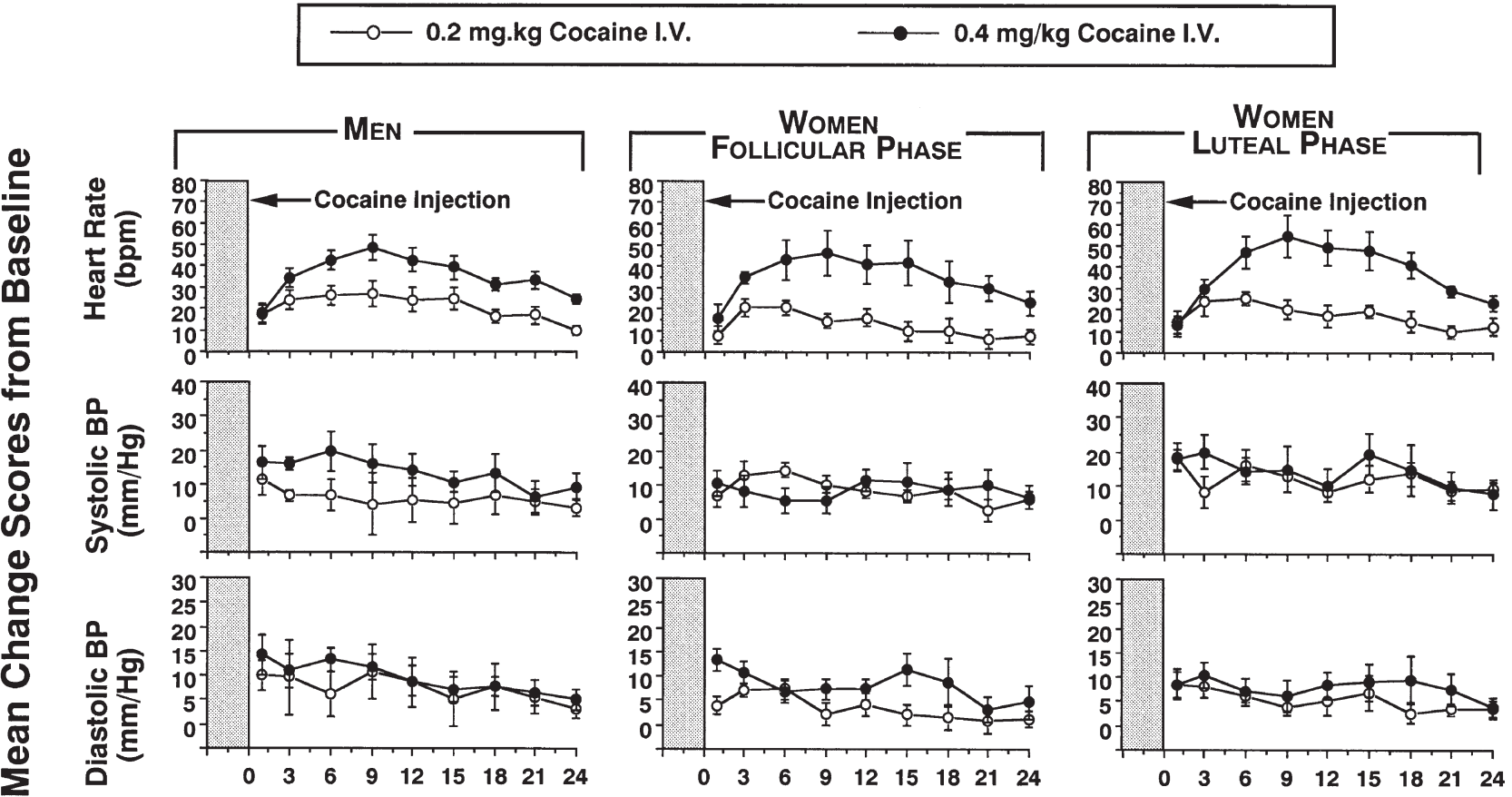

Time after I.V. Cocaine (min)

Figure 1. Cardiovascular effects of cocaine in men and women. Cardiovascular measures in men (left panel), women during the follicular phase of the menstrual cycle (center panel) and women during the luteal phase of the menstrual cycle (right panel) are shown after administration of $0.2 \mathrm{mg} / \mathrm{kg}$, i.v. cocaine (open circles) and $0.4 \mathrm{mg} / \mathrm{kg}$, i.v. cocaine (closed circles). Mean change scores from baseline are shown on each ordinate for heart rate (row 1), systolic blood pressure ( $\mathrm{mm} / \mathrm{Hg}$ ) (row 2) and diastolic blood pressure $(\mathrm{mm} / \mathrm{Hg})$ (row 3$)$. Time $(\mathrm{min})$ after intravenous cocaine administration is shown on the abscissae. Each data point for the $0.2 \mathrm{mg} / \mathrm{kg}$ dose of cocaine is the average ( \pm S.E.M.) of six men, five follicular phase women, and 5 luteal phase women. Each data point for the $0.4 \mathrm{mg} / \mathrm{kg}$ dose of cocaine is the average ( \pm S.E.M.) of six men, six follicular phase women, and six luteal phase women.

average peak levels of $87.6 \pm 3.1 \mathrm{bpm}$. After $0.4 \mathrm{mg} / \mathrm{kg}$ cocaine, heart rate increased by $54.7 \pm 9.7 \mathrm{bpm}$ to average peak levels of $115.3 \pm 6.7 \mathrm{bpm}$.

\section{Subjective Effects of Cocaine}

Peak levels of "high" were reported at 5 minutes after cocaine administration. There was a statistically significant dose-related increase in reports of cocaine-induced "high" for all subjects $(p<.0025)$. The gradual diminution of these effects over time was significantly correlated with the elimination of cocaine from plasma in each group at both cocaine doses $(p<.02-.0003 ; r=$ .88-.99). The intensity of the peak "high" did not differ significantly between men and women at either phase of the menstrual cycle.

\section{DISCUSSION}

\section{Gender Comparisons}

This is the first report of a pharmacokinetic analysis of plasma cocaine levels after controlled intravenous co- caine administration that compares men and women studied during the follicular and luteal phases of the menstrual cycle. The dose of cocaine, rather than gender-related factors, appeared to be the primary determinant of the pharmacokinetic profiles as well as the cardiovascular and subjective effects measured. Peak plasma cocaine levels, heart rate and subjective responses were significantly higher after intravenous ad-

Table 3. Subject Characteristics $-0.4 \mathrm{mg} / \mathrm{kg}$ Cocaine Dose Group

\begin{tabular}{lccc}
\hline Age (years) & Weight $(\mathbf{k g s})$ & Height $(\mathbf{c m s})$ & BMI $\mathbf{( k g / \mathbf { m } ^ { 2 } )}$ \\
\hline \multicolumn{4}{c}{ Males $(\mathrm{n}=6)$} \\
$\overline{\text { X } 29.83}$ & 81.06 & $182.88^{a}$ & 24.50 \\
SE 1.89 & 3.28 & 2.27 & 0.81 \\
\multicolumn{4}{c}{ Female Follicular Phase Group $(n=6)$} \\
x 24.00 & 71.21 & 168.49 \\
SE 0.58 & 4.79 & 2.81 & 24.50 \\
& Female Luteal Phase Group $(n=6)$ & 0.89 \\
x 28.17 & 68.11 & 169.55 \\
SE 2.98 & 4.80 & 1.96 & 23.67 \\
\hline
\end{tabular}

${ }^{a}$ Males were significantly taller than both groups of women $(p=.001)$. 
Table 4. Cocaine Pharmacokinetics After $0.2 \mathrm{mg} / \mathrm{kg}$, i.v. cocaine

\begin{tabular}{lccc}
\hline & Males $(\mathbf{n}=\mathbf{6})$ & Females $(\mathbf{n}=\mathbf{5})$ Follicular Phase & Females $(\mathbf{n}=\mathbf{5})$ Luteal Phase \\
\hline Tmax $(\mathrm{min})$ & $6.7 \pm 2.0$ & $4.0 \pm 1.0$ & $4.8 \pm 1.9$ \\
Cmax $(\mathrm{ng} / \mathrm{ml})$ & $110.8 \pm 17.5$ & $125.9 \pm 16.3$ & $88.1 \pm 20.1$ \\
T $1 / 2(\mathrm{~min})$ & $45.2 \pm 3.7$ & $46.4 \pm 8.2$ & $55.5 \pm 5.4$ \\
AUC $(\mathrm{ng} \cdot \mathrm{min} / \mathrm{ml})$ & $7075 \pm 1173$ & $7509 \pm 1018$ & $6521 \pm 1807$ \\
\hline
\end{tabular}

ministration of $0.4 \mathrm{mg} / \mathrm{kg}$ cocaine than after administration of $0.2 \mathrm{mg} / \mathrm{kg}$ cocaine in men and in women at each phase of the menstrual cycle. However, within each cocaine dose group, there were no significant differences between men and women studied at either phase of the menstrual cycle, in peak plasma cocaine levels, cardiovascular measures or subjective effects "high" measures. Since subjects were matched for BMI and intravenous cocaine was administered on a $\mathrm{mg} / \mathrm{kg}$ basis, these potential sources of variability between men and women were reduced.

Findings in the present study are consistent with an earlier report by Kosten and co-workers (1996) in which no significant gender differences in heart rate, blood pressure or subjective effects measures were detected after administration of $2 \mathrm{mg} / \mathrm{kg}$ intranasal cocaine. Twenty-three men and 11 women of comparable weight ( $68 \mathrm{vs.} 78 \mathrm{~kg}$ ) were studied, but plasma cocaine levels were not reported (Kosten et al. 1996). However, that study of intranasal cocaine administration (Kosten et al. 1996) and our current findings are not in agreement with our previous reports of gender differences after intranasal cocaine administration (Lukas et al. $1995,1996)$. After the same dose of intranasal cocaine $(0.90 \mathrm{mg} / \mathrm{kg})$, six men achieved significantly higher peak plasma cocaine levels than six women and men reported more episodes of "euphoria" than women (Lukas et al. 1995, 1996). There were no gender differences in peak heart rate (Lukas et al. 1996). A number of methodological differences (effective dose, route of administration) may have contributed to the different findings observed after intranasal and intravenous cocaine administration. One important difference is the greater variability inherent in intranasal cocaine administration where subject-specific variables such as depth of inhalation and vital capacity can affect the resulting levels of cocaine in plasma. Moreover, men and women in the intranasal cocaine study were not matched for
BMI; plasma cocaine levels were measured for only 90 min and pharmacokinetic analyses were not performed (Lukas et al. 1996).

\section{Menstrual Cycle Phase Comparisons}

There were no significant differences in peak plasma cocaine levels, cardiovascular or subjective effects measures in women as a function of menstrual cycle phase at either dose of intravenous cocaine. The only significant difference observed between menstrual cycle phases was that follicular phase women reached peak plasma cocaine concentrations more rapidly than men after administration of $0.4 \mathrm{mg} / \mathrm{kg}$ cocaine administration. Although statistically significant, it is unlikely that this 2.7 minutes difference is biologically significant. However, similar differences in the time required to reach peak plasma cocaine levels after intranasal cocaine have been reported (Lukas et al. 1995, 1996). After administration of $0.9 \mathrm{mg} / \mathrm{kg}$ intranasal cocaine, follicular phase women reached peak levels of cocaine in plasma almost twice as fast as luteal phase women (35 vs. $60 \mathrm{~min}$ ) (Lukas et al. 1996).

In contrast to the report by Lukas and co-workers (1996), we did not find statistically significant differences in peak cocaine levels (Cmax) as a function of menstrual cycle phase after intravenous cocaine administration. After intranasal cocaine, women had higher peak plasma cocaine levels during the follicular phase than during the luteal phase $(73.2 \pm 9.9$ vs. $54.7 \pm 8.7$ $\mathrm{ng} / \mathrm{ml}$ ) (Lukas et al. 1996). Differences in methods used to measure subjective effects limit comparisons between the present study and the previous report of subjective effects after intranasal cocaine (Lukas et al. 1996). However, the variability associated with intranasal cocaine administration is suggested by opposite findings on some of the same subjects, studied in the same laboratory under identical conditions (Lukas et al. 1995,

Table 5. Cocaine Pharmacokinetics After $0.4 \mathrm{mg} / \mathrm{kg}$, i.v. cocaine

\begin{tabular}{lccc}
\hline & Males $(\mathbf{n}=\mathbf{6})$ & Females $(\mathbf{n}=\mathbf{6})$ Follicular Phase & Females $(\mathbf{n}=\mathbf{6})$ Luteal Phase \\
\hline Tmax $(\mathrm{min})$ & $8.0 \pm 1.0^{a}$ & $4.0 \pm 0.5$ & $6.7 \pm 0.8$ \\
Cmax $(\mathrm{ng} / \mathrm{ml})$ & $231.3 \pm 22.7$ & $285.3 \pm 24.8$ & $271.8 \pm 36.3$ \\
T 1 2 (min) & $47.5 \pm 4.1$ & $49.1 \pm 6.2$ & $44.1 \pm 3.0$ \\
AUC $(\mathrm{ng} \cdot \mathrm{min} / \mathrm{ml})$ & $16019 \pm 1033$ & $19607 \pm 1914$ & $17283 \pm 2853$ \\
\hline
\end{tabular}

${ }^{a}$ Tmax in males was significantly $(p<.05)$ higher than in follicular phase females. 
1996). After $0.9 \mathrm{mg} / \mathrm{kg}$ intranasal cocaine, six women had lower plasma cocaine levels during the luteal phase than during the follicular phase and these differences in cocaine levels were associated with an attenuated response to cocaine (Lukas et al. 1995). Subsequently, it was reported that there were no differences in subjective reports of cocaine's effects in seven luteal and follicular phase women, despite significant differences in peak plasma cocaine levels (Lukas et al. 1996).

\section{Comparisons of Plasma Cocaine Levels and Heart Rate Increases with Previous Studies in Men}

We are unaware of previous controlled studies of i.v. cocaine in women so comparisons will be limited to previous studies in men. However, in several studies with men, cocaine was administered on the basis of total mg (Cone 1995; Teoh et al. 1993, 1994) rather than adjusted for individual body weight on a $\mathrm{mg} / \mathrm{kg}$ basis. Peak plasma cocaine levels in the present study averaged 110 and $231 \mathrm{ng} / \mathrm{ml}$ after intravenous administration of 0.2 and $0.4 \mathrm{mg} / \mathrm{kg}$ cocaine, respectively. These plasma cocaine levels were similar to those observed at the same doses of cocaine in earlier studies. For example, peak plasma cocaine levels averaged $101 \mathrm{ng} / \mathrm{ml}$ after administration of $0.2 \mathrm{mg} / \mathrm{kg}$, i.v. cocaine (Sholar et al. 1998). A dose of $30 \mathrm{mg}$, i.v. cocaine in a $70 \mathrm{~kg}$ male is roughly equivalent to $0.43 \mathrm{mg} / \mathrm{kg}$ and peak plasma cocaine levels averaged about $260 \mathrm{ng} / \mathrm{ml}$ (Teoh et al. 1993).

The Cmax cocaine values for men in this study (110 $\mathrm{ng} / \mathrm{ml}$ following $0.2 \mathrm{mg} / \mathrm{kg}$, i.v. and $231 \mathrm{ng} / \mathrm{ml}$, following $0.4 \mathrm{mg} / \mathrm{kg}$, i.v.) were almost identical to peak cocaine levels for men following intravenous administration of doses very similar to those administered in the present study (Evans et al. 1996). Although doses were not given on a $\mathrm{mg} / \mathrm{kg}$ basis in that study, the highest dose administered $(32 \mathrm{mg}$ ) would be the equivalent of $0.45 \mathrm{mg} / \mathrm{kg}$ for a $70 \mathrm{~kg}$ man (cf. Evans et al. 1996). Evans and co-workers (1996) noted "The time to achieve peak venous cocaine concentrations after i.v. administration (4 to $5 \mathrm{~min}$ ) is remarkably consistent in the current study and across other studies (Cone 1995; Foltin and Fischman 1992b; Foltin et al. 1990; Javaid et al. 1978; Jeffcoat et al. 1989; Perez-Reyes et al. 1994) despite differences in the rates of administration $(10 \mathrm{sec}$ to $1 \mathrm{~min}) . "$ The Tmax for men observed in this report is also consistent with data from previous clinical studies.

The increases in blood pressure and heart rate observed in this study are also comparable to those reported by other investigators. Peak increases in heart rate to about 90 and $100 \mathrm{bpm}$ were reported after 16 and 32 mg, i.v. cocaine (Foltin and Fischman 1991) and peak increases to about $100 \mathrm{bpm}$ were reported in polydrug abusers after $16 \mathrm{mg}$, i.v. cocaine (Foltin and Fischman 1992a). The time course of increases in heart rate, systolic and diastolic blood pressure after intravenous cocaine in the present study were comparable to those reported by others (Foltin and Fischman 1991, 1992a).

\section{Implications of These Findings}

The lack of significant gender differences in cocaine pharmacokinetics after intravenous administration suggests that these parameters alone cannot explain the gender differences in cocaine-related toxicity observed in human cocaine abusers (Levin et al. 1994) or in rodents (Downs and Eddy 1932; Guerrero et al. 1965; Morishima et al. 1993). Further exploration of other variables, including neuroendocrine differences between men and women may be necessary to clarify the gender-related differences in cocaine's effects. However, from the perspective of medications development, the lack of differences in cocaine pharmacokinetics for men and women may be an advantage. For example, these data suggest that medications based on enhancement of cocaine catabolism would be effective in both men and women.

\section{ACKNOWLEDGMENTS}

This research was supported in part by grants P50-DA04059, K05-DA00101，K05-DA00064，K01-DA00329，K08-DA00297, R01-DA10757 and R01-DA09448 from the National Institute on Drug Abuse, NIH.

\section{REFERENCES}

Abusada GM, Abukhalaf IK, Alford DD, Vinzon-Bautista I, Pramanik AK, Ansari NA, Manno JE, Manno BR (1993): Solid-phase extraction and GC/MS quantitation of cocaine, ecgonine methyl ester, benzoylecgonine, and cocaethylene from meconium, whole blood, and plasma. J Anal Toxicol 17:353-358

Barnett G, Hawks R, Resnick R (1981): Cocaine pharmacokinetics in humans. J Ethnopharmacol 3:353-366

Chow MJ, Ambre JJ, Ruo TI, Atkinson AJ, Bowsher DJ, Fischman MW (1985): Kinetics of cocaine distribution, elimination, and chronotropic effects. Clin Pharmacol Ther 38:318-324

Cone EJ (1995): Pharmacokinetics and pharmacodynamics of cocaine. J Analytical Toxicol 19:459-478

Cone EJ, Kumor K, Thompson LK, Sherer M (1988): Correlation of saliva cocaine levels with plasma levels and with pharmacologic effects after intravenous cocaine administration in human subjects. J Anal Toxicol 12:200-206

Cook CE, Jeffcoat AR, Perez-Reyes M (1985): Pharmacokinetic studies of cocaine and phencyclidine in man. In Barnett G, Chiang CN (eds), Pharmacokinetics and Pharmacodynamics of Psychoactive Drugs: A Research Monograph. Foster City, CA, Biomedical Publications, pp 48-74 
Craft RM, Stratmann JA (1996): Discriminative stimulus effects of cocaine in female versus male rats. Drug Alc Depend 42:27-37

Dickerson GA, Waters IW, Wilson MC, Davis WM (1991): Effect of sex steroids on cocaine lethality in male and female mice. Gen Pharmacol 22:553-557

Downs AW, Eddy NB (1932): The effect of repeated doses of cocaine on the rat. J Pharmacol Exp Ther 46:199-200

Evans SM, Cone EJ, Henningfield JR (1996): Arterial and venous cocaine plasma concentrations in humans: Relationship to route of administration, cardiovascular effects and subjective effects. J Pharmacol Exp Ther 279:1345-1356

FDA (1993a): Food and Drug Administration Guideline for the Study and Evaluation of Gender Differences in the Clinical Evaluation of Drugs National Institute of Health Guide for Grants and Contract, Department of Human Services, Vol 22. Rockville, MD, US Government Printing Office

FDA (1993b): Important Information for Health Professionals from the U.S. Food and Drug Administration Department of Health and Human Services, 3rd ed. Rockville, MD, US Government Printing Office

Foltin RW, Fischman MW (1991): Smoked and intravenous cocaine in humans: Acute tolerance, cardiovascular and subjective effects. J Pharmacol Exp Ther 257:247-261

Foltin RW, Fischman MW (1992a): The cardiovascular and subjective effects of intravenous cocaine and morphine combinations in humans. J Pharmacol Exp Ther 261: 623-632

Foltin RW, Fischman MW (1992b): Self-administration of cocaine by humans: Choice between smoked and intravenous cocaine. J Pharmacol Exp Ther 261:841-849

Foltin RW, Fischman MW, Nestadt G, Stromberger H, Cornell EE, Pearlson GD (1990): Demonstration of naturalistic methods for cocaine smoking by human volunteers. Drug Alcohol Depend 26:145-154

Glick SD, Hinds PA, Shapiro RM (1983): Cocaine-induced rotation: Sex-dependent differences between left- and right-sided rats. Science 221:775-777

Guerrero S, Gallardo A, Munoz C (1965): Gonadal influences upon the sex differences in the resistance to toxic effects of cocaine in rats. Arch Biol Med Exp 2:51-54

Haney M, Castanon N, Cador M, Le Moal M, Mormede P (1994): Cocaine sensitivity in Roman High and Low Avoidance rats is modulated by sex and gonadal hormone status. Brain Res 645:179-185

Haney M, Maccari S, Le Moal M, Simon H, Piazza PV (1995): Social stress increases the acquisition of cocaine selfadministration in male and female rats. Brain Res 698:46-52

Heesch CM, Negus BH, Bost JE, Keffer JH, Snyder III RW, Eichhorn EJ (1996): Effects of cocaine on anterior pituitary and gonadal hormones. J Pharmacol Exp Ther 278:1195-1200

Isenschmid DS, Fischman MW, Foltin RW, Caplan YH (1992): Concentration of cocaine and metabolites in plasma of humans following intravenous administration and smoking of cocaine. J Anal Toxicol 16:311-314

Javaid JI, Fischman MW, Schuster CR, Dekirmenjian H,
Davis JM (1978): Cocaine plasma concentration: Relation to physiological and subjective effects in humans. Science 202:227-228

Javaid JI, Musa MN, Fischman M, Schuster CR, Davis JM (1983): Kinetics of cocaine in humans after intravenous and intranasal administration. Biopharm Drug Dispo $4: 9-18$

Jeffcoat AR, Perez-Reyes M, Hill JM, Sadler BM, Cook CE (1989): Cocaine disposition in humans after intravenous injection, nasal insufflation (snorting), or smoking. Drug Metab Dispo 17:153-159

Kaufman MJ, Levin JM, Ross MH, Lange N, Rose SL, Kukes TJ, Mendelson JH, Lukas SE, Cohen BM, Renshaw PF (1998): Cocaine-induced cerebral vasoconstriction detected in humans with magnetic resonance angiography. JAMA 279:376-380

Kogan MJ, Verebey KG, DePace AC, Resnick RB, Mule SJ (1977): Quantitative determination of benzoylecgognine and cocaine in human biofluids by gas-liquid chromatography. Anal Chem 49:1965-1969

Kosten TR, Kosten TA, McDougle CJ, Hameedi FA, McCance EF, Rosen MI, Oliveto AH, Price LH (1996): Gender differences in response to intranasal cocaine administration to humans. Biol Psychiatry 39:147-148

Kuhn C, Francis R (1997): Gender difference in cocaineinduced HPA axis activation. Neuropsychopharmacology 6:399-407

Levin JM, Holman BL, Mendelson JH, Teoh SK, Garada B, Johnson KA, Springer S (1994): Gender differences in cerebral perfusion in cocaine abuse: Technetium-99mHMPAO SPECT study of drug-abusing women. J Nucl Med 35:1902-1909

Lukas SE, Sholar M, Lundahl LH, Lamas X, Kouri E, Wines JD, Kragie L, Mendelson JH (1996): Sex differences in plasma cocaine levels and subjective effects after acute cocaine administration in human volunteers. Psychopharmacology 125:346-354

Lukas SE, Sholar MB, Fortin M, Wines JJ, Mendelson JH (1995): Gender and menstrual cycle influences on cocaine's effects in human volunteers. In LS Harris (ed), Problems of Drug Dependence, 1994: Proceedings of the 56th Annual Scientific Meeting. NIDA Research Monograph No 153. Rockville, MD, The College on Problems of Drug Dependence, Inc., US Department of Health and Human Services p. 490

Mello NK, Mendelson JH, Drieze J, Kelly M (1990): Acute effects of cocaine on prolactin and gonadotropins in female rhesus monkey during the follicular phase of the menstrual cycle. J Pharmacol Exp Ther 254:815-823

Mello NK, Sarnyai Z, Mendelson JH, Drieze JM, Kelly M (1993): Acute effects of cocaine on anterior pituitary hormones in male and female rhesus monkeys. J Pharmacol Exp Ther 266:804-811

Mello NK, Sarnyai Z, Mendelson JH, Drieze JM, Kelly M (1995): The acute effects of cocaine on anterior pituitary hormones in ovariectomized rhesus monkeys. J Pharmacol Exp Ther 272:1059-1066

Mendelson JH, Sholar M, Mello NK, Teoh SK, Sholar JW (1998): Cocaine tolerance: Behavioral, cardiovascular and neuroendocrine function in men. Neuropsychopharmacology 18:263-271 
Mendelson JH, Teoh SK, Mello NK, Ellingboe J, Rhoades E (1992): Acute effects of cocaine on plasma adrenocorticotropic hormones, luteinizing hormone and prolactin levels in cocaine-dependent men. J Pharmacol Exp Ther 263:505-509

Merkatz RB, Temple R, Sobel S, Feiden K, Kessler DA (1993): Women in clinical trials of new drugs: A change in food and drug administration policy. N Engl J Med 329:292296

Morishima HO, Abe Y, Matsuo M, Akiba K, Masaoka T, Cooper TB (1993): Gender-related differences in cocaine toxicity in the rat. J Lab Clin Med 122:157-163

Morse AC, Erwin VG, Jones BC (1993): Strain and housing affect cocaine self-selection and open-field locomotor activity in mice. Pharmacol Biochem Behav 45:905-912

Perez-Reyes M, Jeffcoat AR, Myers M, Sihler K, Cook CE (1994): Comparison in humans of the potency and pharmacokinetics of intravenously injected cocaethylene and cocaine. Psychopharmacology 116:428-432

Rapp U, Kourounakis P, Selye H (1979): Effect of steroids and diethylstilbestrol on cocaine toxicity, plasma concentrations and urinary excretion. Drug Research 29: $48-50$

Sarnyai Z, Mello NK, Mendelson JH, Eros-Sarnyai M, Mercer $G$ (1996): Effects of cocaine on pulsatile activity of the hypothalamic-pituitary-adrenal axis in male rhesus monkeys: Neuroendocrine and behavioral correlates. J Pharmacol Exp Ther 277:225-234

Sarnyai Z, Mello NK, Mendelson JH, Nguyen P, Erös-Sarnyai M (1995): Effects of cocaine and corticotropin-releas- ing factor (CRF) on pulsatile ACTH and cortisol release in ovariectomized rhesus monkeys. J Clin Endocrinol Metab 80:2745-2751

Selye H (1971): Protection by estradiol against cocaine, coniine, ethylmorphine, LSD, and strychnine. Horm Behav 2:337-341

Sholar MB, Mendelson JH, Mello NK, Siegel AJ, Kaufman MJ, Levin JM, Renshaw PF, Cohen BM (1998): Concurrent pharmacokinetic analysis of plasma cocaine and adrenocorticotropic hormone (ACTH) in men. J Clin Endocrinol Metab 83:966-968

Teoh SK, Mendelson JH, Mello NK, Kuehnle J, Sintavanarong P, Rhoades EM (1993): Acute interactions of buprenorphine with intravenous cocaine and morphine: An investigational new drug phase I safety evaluation. J Clin Psychopharmacol 13:87-99

Teoh SK, Sarnyai Z, Mendelson JH, Mello NK, Springer SA, Sholar JW, Wapler M, Gelles H (1994): Cocaine effects on pulsatile secretion of ACTH in men. J Pharmacol Exp Ther 270:1134-1138

van Haaren F, Hughes CE (1990): Cocaine-induced conditioned taste aversions in male and female Wistar rats. Pharmacol Biochem Behav 37:693-696

van Haaren F, Meyer ME (1991): Sex differences in locomotor activity after acute and chronic cocaine administration. Pharmacol Biochem Behav 39:923-927

Yen SSC (1991): The human menstrual cycle: Neuroendocrine regulation. In Yen SSC, Jaffe RB (eds), Reproductive Endocrinology, 3rd ed. Philadelphia, W.B. Saunders Co. pp 273-308 